\title{
Essential Oil Steam Distillation: Manufacturing 4.0
}

\author{
Carlos Alberto Tosta Machado ${ }^{1 *}$, Herman Augusto Lepikson ${ }^{1}$, Matheus Antônio Nogueira de Andrade ${ }^{2}$, \\ Paulo Renato Câmera da Silva ${ }^{2}$ \\ ${ }^{1}$ Senai Cimatec University Center; ${ }^{2}$ Federal University of Bahia; Salvador,Bahia, Brazil
}

\begin{abstract}
Smart sensors, self-configuration, operational flexibility, and automatic learning, among others, are technological attributes from industry 4.0 appliable to the essential oil extraction by the steam distillation process. These operations are recognized by their simplicity. Nevertheless, lack of automatic controls, process monitoring, and self-adjustment lead to uncontrolled extraction, poor yields, low quality of products. It occurs because of overexposure to high temperatures and overspending resources like energy and water. As far as capacity utilization is concerned, the optimized process is key to planning and managing the production activities. Keywords: Essential Oils. Technology. Yield. Quality. Industry 4.0.
\end{abstract}

Abbreviations: EO: Essential Oil(s); AI: Artificial Intelligence; SOP: Standard Operating Procedure,

\section{Introduction}

The essential oil industry is a primary supplier to cosmetics, pharmaceutical, and homecare businesses. Besides, the market trend towards natural products justifies the increasing interest in these aromatic substances [1]. Nevertheless, regarding technology updates, there are opportunities [2,3] brought up by the wave called industry 4.0: process integration, intelligent sensors, self-configuration, among others [4].

This paper emphasizes how the " 4.0 " attributes can deliver significant improvements to the EO industry as well as sets directional propositions for ideas and developments in future research.

\section{Essential Oil Industry}

The basic steam distillation processes require a few pieces of equipment, being recognized by their simple configuration and operation. Figure 1 shows a sketch of the steam flowing from the generator to the extraction vessel. It vaporizes and carries the essential oil to be liquified in the

Received on 18 May 2021; revised 30 July 2021.

Address for correspondence: Carlos Alberto Tosta Machado. SENAI CIMATEC. Avenida Orlando Gomes, Número 1845 Piatã, Zip Code: 41650-010, Salvador, Bahia, Brazil. E-mail: carlos.tosta@uol.com.br.

J Bioeng. Tech. Appl. Health 2021;4(3):95-99.

(C) 2021 by SENAI CIMATEC. All rights reserved. condenser and separated by the difference in density $[5,6]$. Essential oil floats and is extracted through the upper outlet while the other part of the condensed liquid, called hydrosol [7], is extracted through the bottom of the separation vessel.

These operations handle a broad portfolio of products, processing several types and specimens as feedstock, each of them with its process particularities [8]. The essential oil quality and yield are affected by several conditions like weather, season, rain or irrigation, sun incidence, soil, and plant age [9]. These differences should be detected, compensated, or corrected by the extraction process itself, which is difficult when operating without a proper level of automation. Regular plant floor practices include fixed procedures, times, temperatures, and so on, disregarding specific behaviors of the plant, even when processing the same specimen, different crops, or harvested in diverse conditions.

\section{Main Process Parameters}

The yield and quality of the extracted EO are determined by a series of inputs to the process. Regarding the raw material, once the herb from what EO will be extracted is defined, it is necessary to determine the best condition to feed the extractor: fresh, dehydrated and the drying conditions (sun, shadow, drying time, etc.), 
Figure 1. Basic EO steam distillation process.

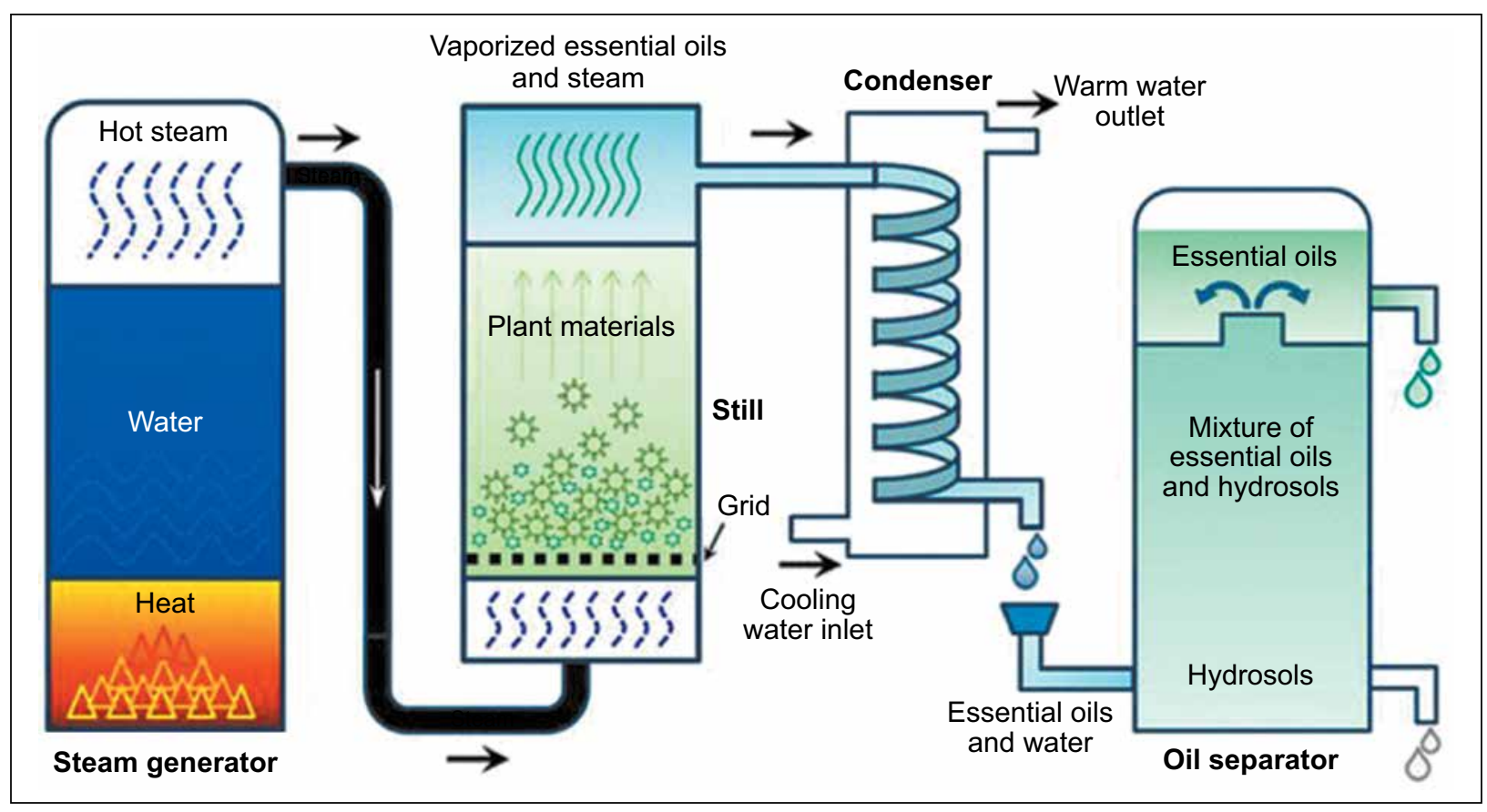

chopped or not, particle size, and, regarding the process, steam temperature, pressure, and flowrate; cooling water flow rate and temperature [10]. Beyond these basic parameters, during the extraction process, undesired occurrences may happen to require detection and correction. Some of these occurrences are responsible for lowering yield and making product quality poorer. The optimum process time, the relationship between cooling temperature and essential oil yield and quality, the possibility of product degradation issues to be addressed by technology, when properly designed [11].

\section{Undesired and Unknown Process Occurrences}

In such non-automated conditions, operators cannot execute accurate process control. If there are no proper corrections during the process, the results are evidenced after the end or, worst, when the customer analyzes the product.

SOP (Standard Operating procedure) or just by historic practices fixed and defined the process duration. However, it would result in several problems such as product degradation because of excessive exposition to high temperature; energy, and water overuse; equipment capacity utilization beyond the optimum required to deliver the production plan, and, eventually, product rejection by the customer. Figure 2 shows an example of product degradation in geranium essential oil.

Possible product degradation root causes could be the excessive process time and the uneven steam stream flowing through the green mass, inside the extractor. Proper smart sensors and actuators can solve these problems.

The relation between condensation water temperature and yield and product quality is another issue. When volatile components are lost, yield decreases, and they are not analytically detected, in chromatography for instance (or detected in smaller quantities) [12].

So, the present paper brings a proposal for the EO industry, adding technological features to contribute to better yield and quality.

\section{The Proposed EO "4.0" Process}

The basic process control features to the EO industry would bring significant improvements to this industry segment $[13,14]$. Figure 3 displays a 
Figure 2. Geranium EO degradation.
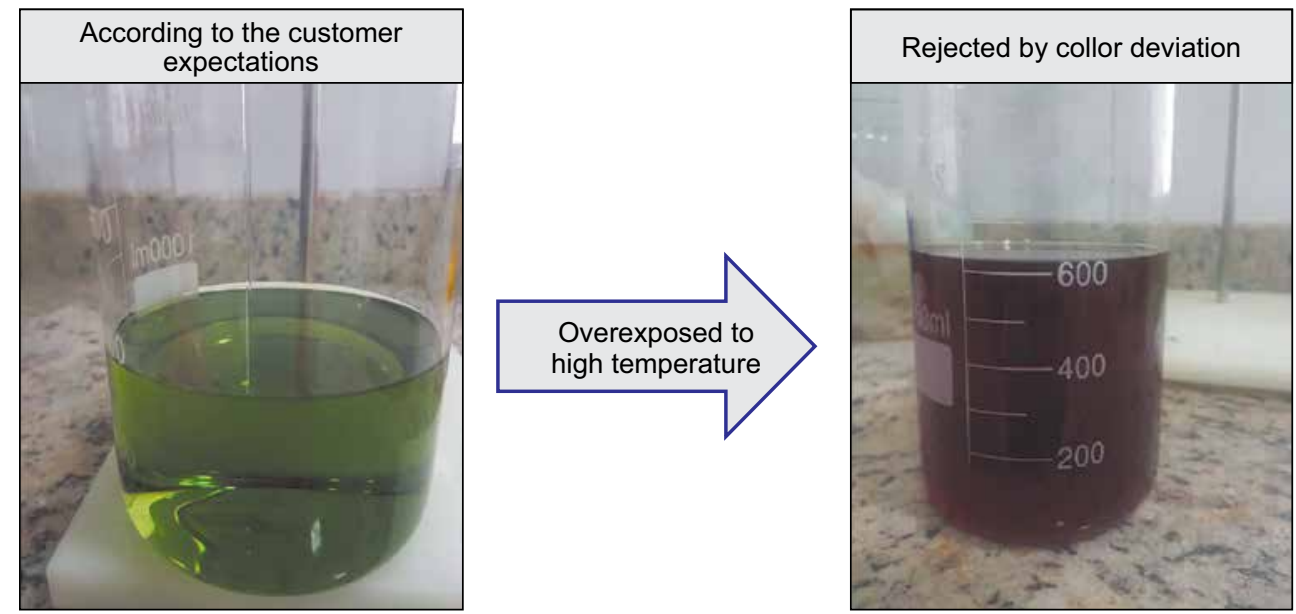

Figure 3. Essential oil plant: current and proposed configurations.

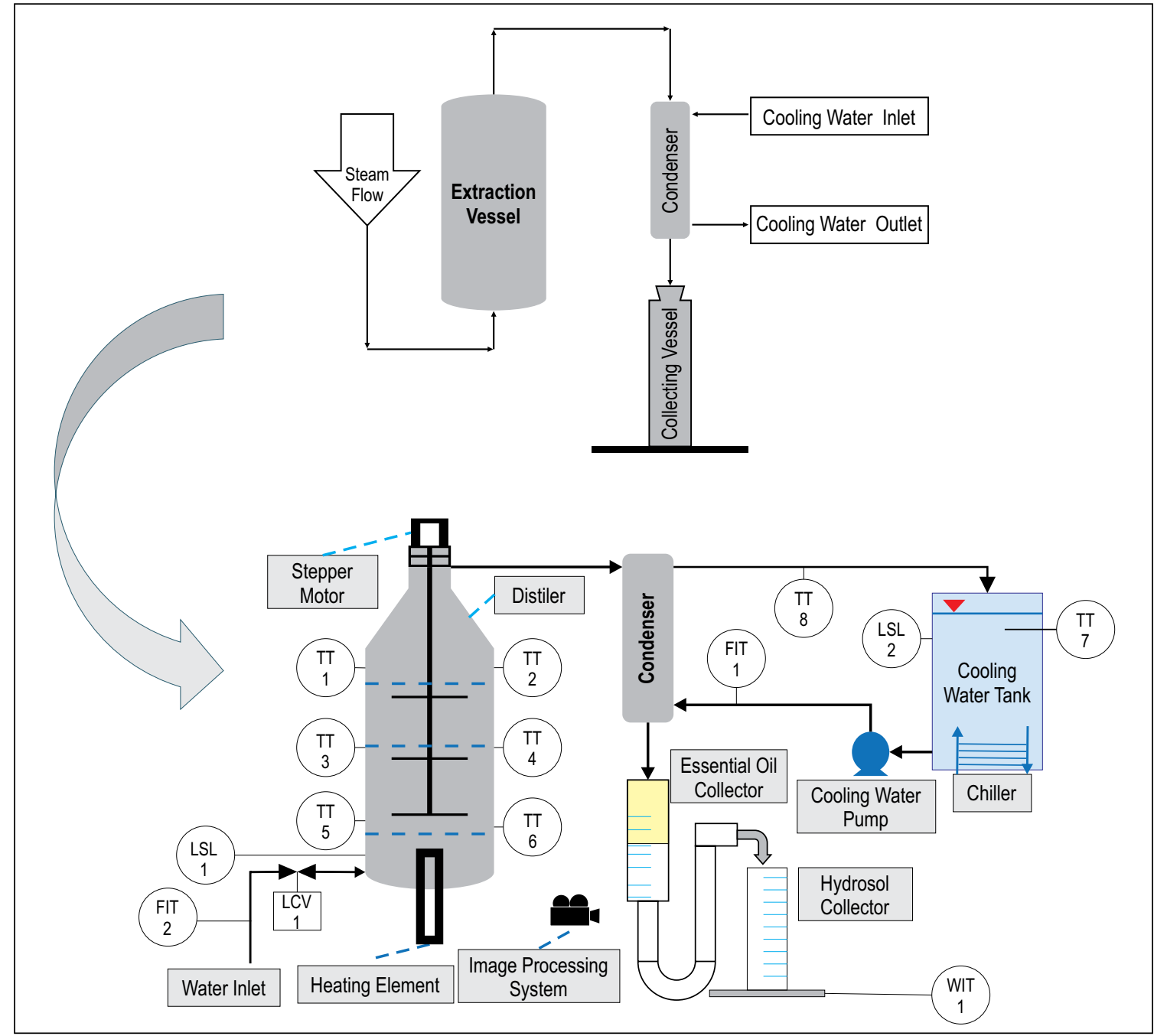

FIT: Flow Indicator and Transmitter; LCV: Level Control Valve; LSL: Level Switch Low; TT: Temperature Transmiter; WIT: Weight indicator/transmitter. 
proposal, but it must become clear that the "one size fits all" would not be the case: the design of a " 4.0 " plant must be made to deliver what is necessary case by case.

Conventional controllers could be applied, nevertheless, the way their installation is designed and executed is the touchstone to detect these undesired process occurrences inside the green mass; the image processing system is a way of detecting optimum process time. AI (Artificial Intelligence) can indicate promising correlations among data and "propose" optimized process parameters, via - for instance - a digital twin [14].

\section{End of Process Discussion}

The economic end-of-process time occurs much sooner than the one used as standard practice in the industry. In this specific case, the extraction of lemongrass, determined by the industry SOP, is two hours. Nevertheless, the economic time is 40 minutes (Graphic 1).

It means that the period when the extracted essential oil value is lower than the overall manufacturing expenses or, at least, energy cost, the process should be stopped. Figure 4 illustrates how the optimum end-ofprocess time could be determined.

Graphic 1. Extraction curve: yield x time.

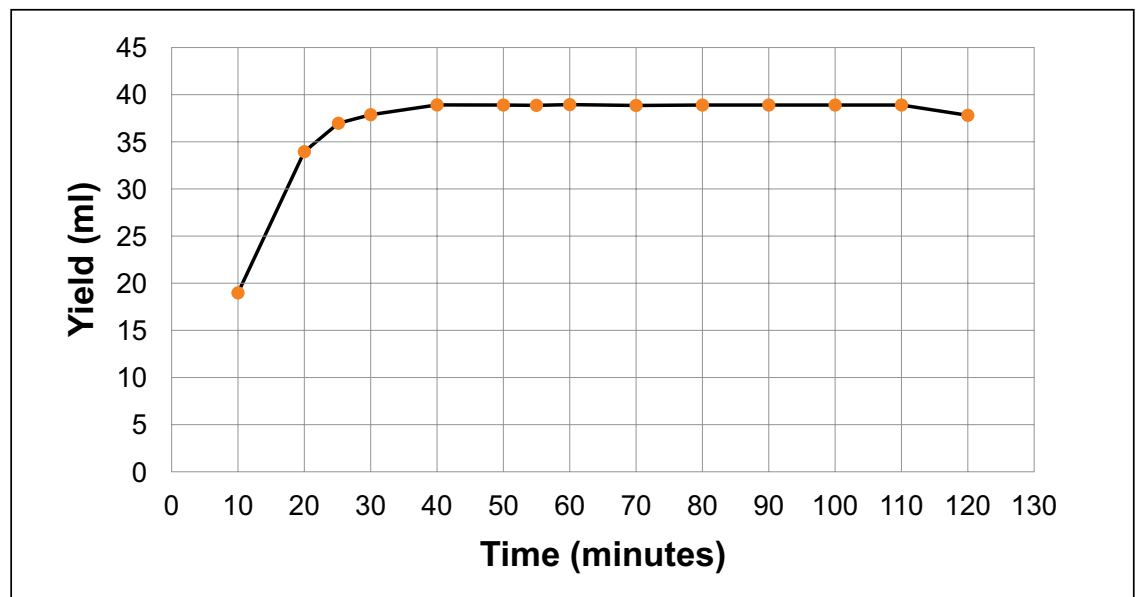

Figure 4. Image processing system.

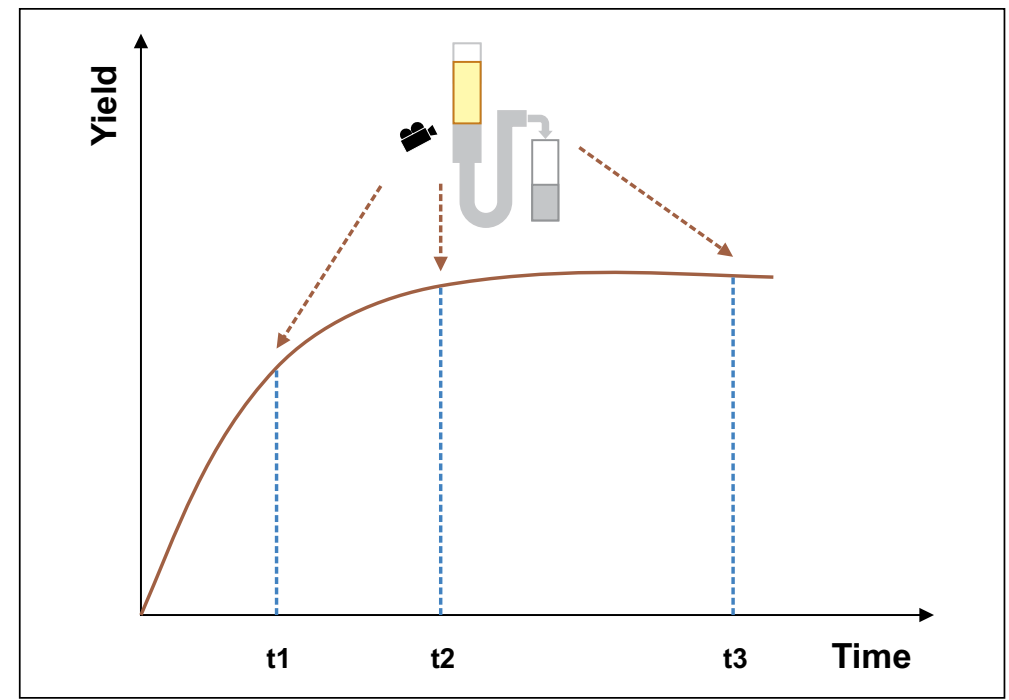


The period between the start and $\mathrm{t} 1$ is the maximum slope, meaning the highest amount of EO should be extracted by the unit of time. In the period between $\mathrm{t} 1$ and $\mathrm{t} 2$ occurs the point of economical duration, which means, the amount (value) of EO extracted still justifies the continuation. The period between $\mathrm{t} 2$ and $\mathrm{t} 3$ represents the standard procedure time. However, without effective extraction, meaning a waste of energy, water, and production capacity. Beyond that, this period may cause product degradation due to overexposure to high temperatures or even lowering yield due to evaporation of light fractions.

\section{Conclusion}

Yield and quality are attached and are critical to the essential oil process. Technological attributes have the potential to manage process information and enhance steam distillation extraction. It is a must for the EO industry to climb the stairs towards manufacturing excellence. Technology is key to reaching that goal.

\section{Acknowledgments}

FAPESB - "Fundação de Amparo à Pesquisa do Estado da Bahia" through the research grant awarded (5633/2019).

\section{References}

1. Ali B, et al. Essential oils used in aromatherapy: A systemic review. Asian Pacific Journal of Tropical Biomedicine 2015;(5)8:601-611.
2. Chávez MGC. Hidrodestilacion de aceites esenciales: modelado y caracterizacion. 2007. Tese de Doutorado. Universidad de Valladolid.

3. Johari SNH, et al. Real-time IMC-PID control and monitoring of essential oil extraction process using IoT. In: 2020 IEEE International Conference on Automatic Control and Intelligent Systems (I2CACIS). IEEE 2020:51-56.

4. SchmacherA, Erol S, Sihn W.Amaturity model for assessing Industry 4.0 readiness and maturity of manufacturing enterprises. Procedia Cirp 2016;52:161-166.

5. Weng DCJ, et al. Optimal extraction and evaluation on the oil content of citronella oil extracted from Cymbopogon nardus. Malaysian Journal of Analytical Sciences 2015;(19)1:71-76.

6. El Asbahani A, et al. Essential oils: From extraction to encapsulation. International Journal of Pharmaceutics 2015;483:1-2.

7. Catty S. Hydrosols: the next aromatherapy. Inner Traditions/Bear \& Co, 2001.

8. Uhlenbrock L, et al. Natural products extraction of the future-sustainable manufacturing solutions for societal needs. Processes 2018;(6)10:177

9. Moghaddam M, Mehdizadeh L. Chemistry of essential oils and factors influencing their constituents. In: Soft chemistry and food fermentation. Academic Press 2017:379-419.

10. Hanaa ARM, et al. Lemongrass (Cymbopogon citratus) essential oil as affected by drying methods. Annals of Agricultural Sciences 2012;(57)2:113-116.

11. Machado C,et al. Technology as a Pillar for Essential Oil Green Extraction. Journal of Bioengineering and Technology Applied to Health 2021;(4)1:9-16.

12. Bozovic M, et al. Essential oils extraction: A 24-hour steam distillation systematic methodology. Natural Product Research 2017;(31)20:2387-2396.

13. Topaloglu F. Industrial Automation and Edge Computing SCADA PLC PAC IO-LINK-2. Turkish Journal of Science and Technology 2021;(16)1:179-185.

14. Xia K, et al. A digital twin to train deep reinforcement learning agent for smart manufacturing plants: Environment, interfaces and intelligence. Journal of Manufacturing Systems 2021;58:210-230. 